\title{
Visual prognosis following treatment of acute central retinal artery obstruction
}

\author{
JAMES J. AUGSBURGER' AND LARRY E. MAGARGAL ${ }^{2}$ \\ From the ${ }^{1}$ Oncology Service and the ${ }^{2}$ Retinal Vascular Unit, Retina Service, Wills Eye Hospital, \\ Jefferson Medical College, Thomas Jefferson University, Philadelphia, Pennsylvania, USA
}

SUMMARY The authors report the visual outcome in 34 consecutive cases of treated acute central retinal artery obstruction. Visual acuity equal to or better than $6 / 30$ was recovered in $35 \%$ of the cases. The presenting visual acuity and duration of visual impairment appear to correlate with visual prognosis.

The prognosis for useful vision after central retinal artery obstruction is generally considered poor, except in those cases in which a patent cilioretinal artery supplies the fovea. ${ }^{1}$ Consequently various therapeutic regimens have been devised for this condition. The efficacy and limitations of many of these regimens have been reviewed in detail by ffytche. ${ }^{2}$ Some patients have been reported to regain useful vision after treatment. ${ }^{3-11}$

The authors initiated a prospective but uncontrolled study of patients with spontaneous acute central retinal artery obstruction in order to evaluate their visual prognosis following treatment. This report describes our treatment regimen and relates our experience with 34 consecutive cases.

\section{Patients and methods}

All patients referred to the Retinal Vascular Unit between March 1976 and October 1978 with the diagnosis of acute central retinal artery obstruction were considered for the study. Visual acuity was recorded and a complete ocular examination, including slit-lamp biomicroscopy, applanation tonometry, and ophthalmoscopy, was performed. The affected eye was studied by fluorescein angiography and electroretinography to confirm the clinical diagnosis. The diagnosis was considered to be established only if the affected eye showed fundus features typical of acute central retinal artery obstruction, a typical fluorescein angiographic appearance, and characteristic electrophysiological responses. Patients with a fovea-sparing cilioretinal artery were excluded.

Every patient underwent treatment according to

Correspondence to Dr J. J. Augsburger, Oncology Service, Wills Eye Hospital, 9th and Walnut Streets, Philadelphia, Pa 19107, USA. our regimen. This treatment was begun immediately after the diagnosis had been established. The treatment ${ }^{12}$ consisted of (1) paracentesis of the anterior chamber under the slit-lamp biomicroscope with topical anaesthesia and the use of a tuberculin syringe and 27 gauge needle; (2) controlled ocular massage using a fundus contact lens while visualising the retinal vessels at the disc; (3) inhalational therapy with a $95 \%$ oxygen $/ 5 \%$ carbon dioxide mixture administered by mask for 10 minutes every hour during the waking hours and every 4 hours during the night; and (4) oral administration of acetazolamide ( $250 \mathrm{mg}$ q.i.d.) and aspirin (10 grains $(65 \mathrm{mg})$ b.i.d.). Every patient underwent a complete physical examination with emphasis on the cardiovascular system. A complete blood count, an erythrocyte sedimentation rate, a serum lipid profile, a fasting blood glucose, an electrocardiogram, and a chest $x$-ray were obtained on admission. Inhalation therapy was discontinued after 48 to $\mathbf{7 2}$ hours, but acetazolamide and aspirin were continued for at least 2 weeks. These drugs were then discontinued unless another indication for their continued use existed. Drugs and dosages for the associated systemic disorders were managed by the internist.

Complete ophthalmic examination was repeated prior to hospital discharge and again at follow-up 1 month or more after treatment. Early (1-2 days) and late (over 2 weeks) post-treatment fluorescein angiograms and electroretinograms were obtained in many of the cases in order to assess the changes in retinal perfusion and electrical retinal responsiveness.

\section{Results}

Thirty-two patients were included in the study. They ranged in age from 32 to 74 years, average 
Fig. I Graph relating duration of visual impairment (ordinate, logarithmic scale), presenting visual acuity and final visual acuity (abscissa) for 34 cases of acute central artery obstruction. The 5 lines on the graph (1-5) are isoacuity curves for presenting visual acuity corresponding to the symbols defined below. The better the presenting visual acuity, the steeper the slope of the isoacuity curve. Symbols indicate presenting visual acuity as follows: NLP (line I); O LP (line 2); $\triangle H M$ (line 3); $\square$ CF at I $m$ (line 4); CF at $1 \mathrm{~m}$ (line 5).

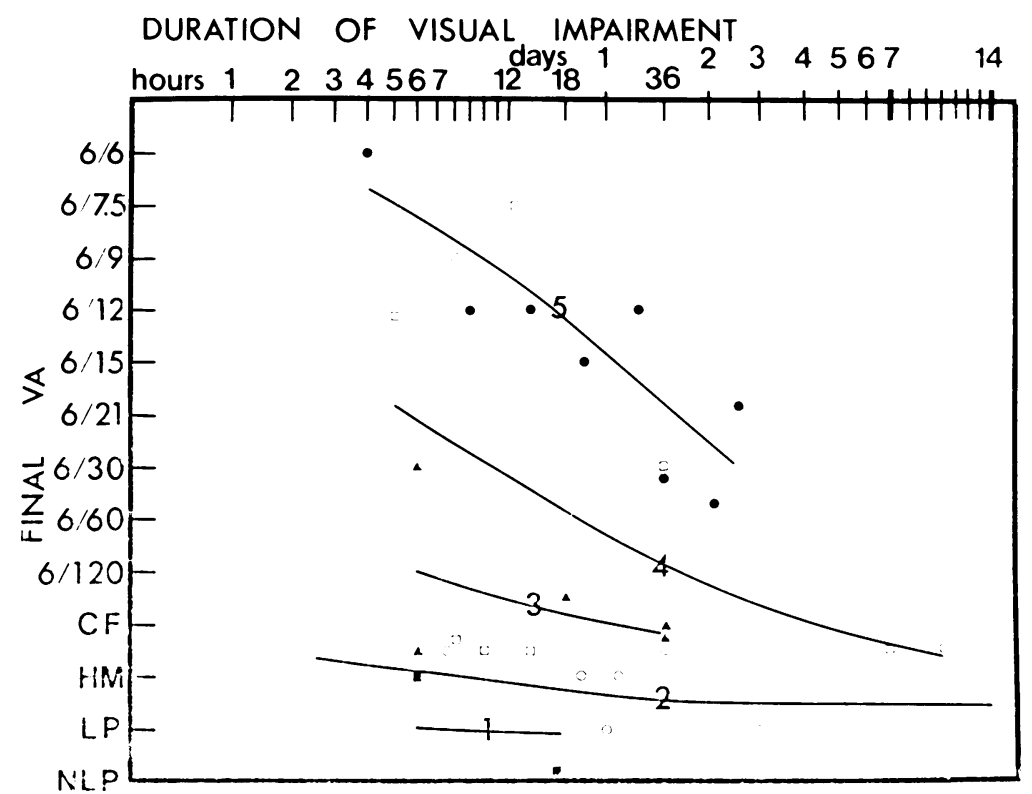

62 years (Table 1). Twenty-five were men $(78 \%)$ and 7 were women. Nineteen were white and 13 were black. The average duration of follow-up was over 2 months (67.8 days). Two patients had recurrent acute central retinal artery obstruction, making the total number of cases 34 . The central retinal artery obstruction occurred in the right eye in $21(61 \%)$ and in the left eye in $13(39 \%)$. The presenting visual acuities ranged from $6 / 60$ to no light perception (Table 1 ). The recognised duration of persistent visual impairment ranged from $2 \cdot 5$ hours to 2 weeks (Table 1) with a median of 19 hours.

A significant improvement in visual acuity was defined as a sustained improvement of 3 or more visual acuity gradations (Fig. 1, ordinate) and a final visual acuity of $6 / 30$ or better on follow-up examination 1 month or more after treatment. Twelve of our 34 cases $(35 \%)$ showed significant improvement in visual acuity (Table 1). Seven of our cases $(21 \%)$ improved by 6 visual acuity gradations or more and achieved a final visual acuity of $6 / 12$ or better. None of our cases had a post-treatment visual acuity worse than the presenting visual acuity. Only 9 of our 34 cases $(26 \%)$ showed no improvement in visual acuity whatsoever.

Seven of the 12 cases that improved significantly had already done so within $\mathbf{4 8}$ hours after initiation of treatment. However, the maximal visual acuity achieved in the 12 cases that showed significant improvement was attained in only 4 within 48 hours. Further visual improvement occurred beyond 48 hours in the remaining 8 cases.
The 12 cases that achieved significant improvement in visual acuity had an average presenting visual acuity of counting fingers (CF) at a distance of greater than $1 \mathrm{~m}$, whereas the 22 cases that did not improve had an average presenting visual acuity of poor hand movement (HM). The difference between these 2 groups is statistically significant $(t=3.95, \mathrm{P}<0.05)$. The average duration of recognised visual impairment prior to initiation of treatment in those cases that showed eventual significant visual improvement was $21 \cdot 1$ hours as compared to 58.6 hours in those cases that did not improve. The longest duration of visual impairment reported by any patient who showed significant visual improvement at follow-up was approximately 72 hours.

Presenting visual acuity and duration of visual impairment are related simultaneously to final visual acuity in Fig. 1. This graph presents the duration of visual impairment in a logarithmic scale on the abscissa to visual acuity on the ordinate (see legend to Fig. 1 and Discussion for interpretation of graph).

Patient age, presence or absence of clinically detected emboli, and clinical evidence of systemic disorders, including hypertension and atherosclerotic vascular disease, were evaluated for any correlation with visual prognosis. No statistically significant correlation was found between the patients who improved visually and those who did not for any of these subgroups. Nine of the 32 eyes $(28 \%)$ had a non-fovea-sparing cilioretinal artery. No statisti- 
Table 1 Clinical data on 34 treated cases of acute central retinal artery obstruction

\begin{tabular}{|c|c|c|c|c|c|c|c|}
\hline Case & Age & Sex & Eye & $\begin{array}{l}\text { Presenting } \\
\text { visual acuity }\end{array}$ & $\begin{array}{l}\text { Duration of } \\
\text { visual impairment }\end{array}$ & $\begin{array}{l}\text { Final visual } \\
\text { acuity }\end{array}$ & $\begin{array}{l}\text { Success }(S) \text { or } \\
\text { failure }(F)^{*}\end{array}$ \\
\hline 1 & 57 & $\mathbf{M}$ & OD & $\mathbf{L P}$ & 2 Weeks & $\mathbf{L P}$ & $\mathbf{F}$ \\
\hline 2 & 32 & $\mathbf{M}$ & OD & $6 / 60$ & $20.5 \mathrm{~h}$ & $6 / 15$ & $\mathbf{S}$ \\
\hline 3 & 59 & $\mathbf{M}$ & OD & $\mathbf{L P}$ & 3 Days & $\mathbf{L P}$ & $\mathbf{F}$ \\
\hline $4 * *$ & 32 & $\mathbf{M}$ & OD & $\mathrm{CF}$ at $>1 \mathrm{~m}$ & $14 \mathrm{~h}$ & $6 / 12-$ & $\mathbf{S}$ \\
\hline 5 & 73 & $\mathbf{M}$ & OD & $\mathrm{CF}$ at $>1 \mathrm{~m}$ & $52 \mathrm{~h}$ & $6 / 60+$ & $\mathbf{F}$ \\
\hline 6 & 71 & $\mathbf{M}$ & os & $\mathbf{L P}$ & $24 \mathrm{~h}$ & $\mathbf{L P}$ & $\mathbf{F}$ \\
\hline 7 & 51 & $\mathbf{M}$ & os & HM & $18 \mathrm{~h}$ & $\mathrm{CF}$ at $>1 \mathrm{~m}$ & $\mathbf{F}$ \\
\hline 8 & 71 & $\mathbf{M}$ & OD & LP & $7 \cdot 5 \mathrm{~h}$ & $\mathrm{CF}$ at $<1 \mathrm{~m}$ & $\mathbf{F}$ \\
\hline 9 & 56 & $\mathbf{M}$ & os & $\mathbf{L P}$ & $20 \mathrm{~h}$ & $\mathbf{H M}$ & $\mathbf{F}$ \\
\hline 10 & 69 & $\mathbf{F}$ & os & $\mathbf{L P}$ & $26 \mathrm{~h}$ & HM & F \\
\hline 11 & 64 & $\mathbf{M}$ & OD & NLP & $17 \mathrm{~h}$ & NLP & $\mathbf{F}$ \\
\hline 12 & 58 & $\mathbf{M}$ & OD & $\mathrm{CF}$ at $>1 \mathrm{~m}$ & 3 Days & $6 / 21$ & $\mathbf{S}$ \\
\hline 13 & 64 & $\mathbf{M}$ & OS & HM & $6 \mathrm{~h}$ & $6 / 30+$ & $\mathbf{S}$ \\
\hline 14 & 63 & $\mathbf{F}$ & OD & $\mathrm{CF}$ at $<1 \mathrm{~m}$ & $5 \mathrm{~h}$ & $6 / 12$ & $\mathbf{s}$ \\
\hline 15 & 74 & $\mathbf{F}$ & os & $\mathrm{CF}$ at $<1 \mathrm{~m}$ & 10 Days & $\mathrm{CF}$ at $<1 \mathrm{~m}$ & $\mathbf{F}$ \\
\hline 16 & 50 & $\mathbf{M}$ & OD & NLP & $6 \mathrm{~h}$ & HM & $\mathbf{F}$ \\
\hline 17 & 54 & $\mathbf{M}$ & OD & HM & $36 \mathrm{~h}$ & $\mathbf{C F}$ & $\mathbf{F}$ \\
\hline 18 & 72 & $\mathbf{M}$ & os & $\mathrm{CF}$ at $<1 \mathrm{~m}$ & $36 \mathrm{~h}$ & $6 / 30$ & $\mathbf{s}$ \\
\hline 19 & 61 & $\mathbf{F}$ & OS & $\mathrm{CF}$ at $>1 \mathrm{~m}$ & $36 \mathrm{~h}$ & $6 / 30$ & $\mathbf{S}$ \\
\hline 20 & 55 & $\mathbf{M}$ & OD & HM & $6 \mathrm{~h}$ & $\mathrm{CF}$ & $\mathbf{F}$ \\
\hline 21 & 63 & $\mathbf{M}$ & os & $\mathbf{L P}$ & $8 \mathrm{~h}$ & $6 / 9$ & $\mathbf{S}$ \\
\hline 22 & 64 & $\mathbf{F}$ & OD & $\mathrm{CF}$ at $<1 \mathrm{~m}$ & $14 \mathrm{~h}$ & HM & $\mathbf{F}$ \\
\hline 23 & 59 & $\mathbf{M}$ & os & $\mathrm{CF}$ at $>1 \mathrm{~m}$ & $9 \mathrm{~h}$ & $6 / 12$ & $\mathbf{s}$ \\
\hline 24 & 58 & $\mathbf{M}$ & OD & $\mathrm{CF}$ at $>1 \mathrm{~m}$ & $30 \mathrm{~h}$ & $6 / 12$ & $\mathbf{S}$ \\
\hline 25 & 61 & $\mathbf{M}$ & OD & $\mathbf{L P}$ & $36 \mathrm{~h}$ & $\mathrm{CF}$ at $<1 \mathrm{~m}$ & $\mathbf{F}$ \\
\hline 26 & 64 & $\mathbf{M}$ & OD & $\mathbf{L P}$ & $2.5 \mathrm{~h}$ & HM & $\mathrm{F}$ \\
\hline 27 & 70 & $\mathbf{F}$ & os & $\mathrm{CF}$ at $<1 \mathrm{~m}$ & 1 Week & HM & $\mathbf{F}$ \\
\hline $28 * * *$ & 58 & $\mathbf{M}$ & OD & $\mathbf{L P}$ & 4 Days & HM & $\mathbf{F}$ \\
\hline 29 & 69 & $\mathbf{F}$ & OD & $\mathbf{L P}$ & 12 Days & $\mathbf{C F}$ & $\mathbf{F}$ \\
\hline 30 & 66 & $\mathbf{M}$ & OD & $\mathrm{CF}$ at $<1 \mathrm{~m}$ & $8 \mathrm{~h}$ & HM & $\mathbf{F}$ \\
\hline 31 & 64 & $\mathbf{M}$ & OD & HM & $36 \mathrm{~h}$ & $\mathrm{CF}$ at $<1 \mathrm{~m}$ & $\mathbf{F}$ \\
\hline 32 & 48 & $\mathbf{M}$ & OD & $\mathrm{CF}$ at $>1 \mathrm{~m}$ & $4 \mathrm{~h}$ & $6 / 6$ & $\mathbf{s}$ \\
\hline 33 & 70 & $\mathbf{M}$ & os & $\mathrm{CF}$ at $<1 \mathrm{~m}$ & $12.5 \mathrm{~h}$ & $6 / 7 \cdot 5$ & $\mathbf{s}$ \\
\hline 34 & 74 & $\mathbf{M}$ & os & $\mathrm{CF}$ at $<1 \mathrm{~m}$ & $10 \mathrm{~h}$ & $\mathrm{CF}$ at $<1 \mathrm{~m}$ & $\mathbf{F}$ \\
\hline
\end{tabular}

*Success $(S)$ and failure $(F)$ as defined in text. **Same patient as case 2 ; reobstruction of central retinal artery OD. ***Same patient as case 24 ; reobstruction of central retinal artery $\mathrm{OD}$. 
cally significant correlation could be found between the presence or absence of such arteries and recovery of visual acuity after central retinal artery obstruction.

The $b$ wave amplitude in the affected eyes evaluated by pretreatment electroretinography was less than in the respective fellow eyes in every case by a proportion ranging from 16 to $46 \%$. The a wave amplitude of the affected eyes ranged from $32 \%$ less than to $12 \%$ greater than that of the respective fellow eyes. The ratio of $b$ wave amplitude to a wave amplitude (b/a ratio) was consistently less in the affected eyes (average 1.29) than in the respective fellow eyes (average 1.68). The group of patients who achieved significant improvement in visual acuity had average reductions of $b$ wave amplitudes and levels of $b / a$ ratios in the affected eyes that were markedly less than those of the group of patients who did not improve visually $(19.5 \%$ average $b$ wave reduction, 1.46 average $b / a$ ratio in improved cases; $41.7 \%$ average $b$ reduction, 1.24 average $b / a$ ratio in unimproved cases).

Pretreatment fluorescein angiograms of our patients showed that none of them had total obstruction of flow into the affected eye via the central retinal artery, in spite of the clinical features indicative of central retinal artery 'occlusion'. Similar observations of the infrequency of demonstrable total obstruction of the central retinal artery by fluorescein angiography in such cases have been reported previously. ${ }^{13}$ On the other hand all our patients studied by pretreatment fluorescein angiography showed delayed retinal arterial filling and a prolonged interval between initial choroidal flush and retinal arterial filling. Furthermore, some of the angiograms showed evidence of abnormal choroidal filling as well.

\section{Comments}

Our results suggested that the prognosis for visual acuity in acute central retinal artery obstruction may not be as dismal as previously believed.

The observation that some of our patients recovered a significant degree of visual acuity indicates that these patients had at least partially reversible impairment of retinal function at the time of presentation. The degree of reversibility appeared to correlate with presenting visual acuity and duration of visual impairment. Fig. 1 shows the interrelationship between these 2 factors and final visual acuity in our 34 cases. The curves on the graph indicate the projected average final visual acuity for eyes with treated acute central retinal artery obstruction separated into 5 levels of presenting visual acuity. In patients with severe visual impairment at presentation (visual acuity light perception or worse, lines 1 and 2 in Fig. 1) the likelihood of significant improvement in visual acuity appears to be small even if the duration has been only 2-4 hours. In contrast the average patient with relatively good presenting vision (visual acuity $\geqslant$ counting fingers at $1 \mathrm{~m}$, line 5 in Fig. 1) can attain a final visual acuity of approximately $6 / 30$ even after a duration of 36-48 hours.

The precise relationship between presenting visual acuity and the degree of impairment of blood flow into the eye via the central retinal artery is not known. Experimental total central retinal artery obstructions in rhesus monkeys of up to 90 minutes' duration have been shown to cause no persistent ophthalmoscopic, angiographic, electrophysiological, or morphological damage to the retina. ${ }^{14}$ Nonperfused retina in monkeys and cats appears to survive central retinal artery occlusion for prolonged periods because of the metabolic contributions of the intact choroidal circulation to the retina.15 Partially perfused retina, which appears to be present in almost all human clinical cases of central retinal artery obstruction, ${ }^{13}$ is probably able to survive in a reversible preinfarction state for a much longer period of time. Restoration of the central retinal artery blood flow, either spontaneously or in response to therapy, permits recovery of visual acuity to a level determined by the viability of the retina at that time. Reduction of the functional severity of the central retinal artery obstruction therapeutically, by means such as abrupt lowering of the intraocular pressure by paracentesis and increasing the retinal oxygenation by inhalation therapy with $95 \%$ oxygen and $5 \%$ carbon dioxide, may prolong the period of retinal viability in a preinfarction ischaemic state. Such treatments may, in effect, provide time for the retinal arterial circulation to undergo alterations that improve retinal perfusion by bypassing or reopening the obstructed artery.

The prognostic significance of the actual recorded $a$ and $b$ wave voltages on the electroretinograms in our cases was difficult to assess. A considerable overlap existed between the range of voltages in the 'normal' fellow eyes and that of the affected eyes. This difficulty has been alluded to previously by Henkes, ${ }^{16}$ who noted that only $22 \%$ of his patients with central retinal artery obstruction had a normal ERG in the unaffected eye. The prognostic significance of fluorescein angiographic intervals was also difficult to assess. We encountered problems of reproducibility in measurement of the various angiographic intervals. Because of these difficulties, we have not found these studies particularly useful as prognostic indicators of the likeli- 
hood of significant visual recovery in our patients. However, the value of these studies as prognostic tools is still being evaluated.

We have attempted to compare the visual recovery rate of our patients with that reported by other investigators.

Lorentzen ${ }^{17}$ reported that none of his 12 cases of central retinal artery obstruction (treatment not specified) showed significant visual improvement (by our criteria). Karjalainen ${ }^{18}$ reported long-term follow-up of 53 patients with prior acute central retinal artery obstruction. Ten of the 53 cases $(19 \%)$ showed significant visual improvement (by our criteria). However, $12 \%$ of the eyes had a patent cilioretinal artery. Henkes ${ }^{16}$ reported that 5 of his 19 cases $(26 \%)$ with visual acuities recorded for both presenting and follow-up examinations showed significant visual acuity improvement (by our criteria) after treatment with intravenous and oral vasodilators. He did not state whether or not any of his cases had a fovea-sparing cilioretinal artery, which is known to improve the visual prognosis. $^{1}$

Brown and Shields ${ }^{1}$ reported on the prevalence and prognostic implications of a patent cilioretinal artery in a retrospective study of acute central retinal artery obstructions. Among their 107 patients $28(26 \%)$ had a patent cilioretinal artery in the affected eye. In 5 of these 28 cases less than half the papillomacular bundle was supplied by the patent cilioretinal artery. Not one of these cases showed significant visual improvement or achieved a visual acuity better than counting fingers. In 11 of these 28 cases the patent cilioretinal artery supplied more than half of the papillomacular bundle but did not spare the fovea. The follow-up visual acuities in these cases ranged from $6 / 30$ to counting fingers. Twelve of their cases had a fovea-sparing cilioretinal artery. All but one of these cases achieved a final visual acuity of $6 / 30$ or better. The authors commented that in acute central retinal artery obstruction with a fovea-sparing cilioretinal artery, 'there is about a $91 \%$ chance that eventual visual acuity will be in the range from $6 / 6$ to $6 / 24$ and about an $83 \%$ chance it will range from $6 / 6$ to $6 / 15$ '.

\section{Conclusion}

This uncontrolled study does not prove the efficacy of our treatment regimen. Without a double-masked controlled study one is unable to exclude the possibility that several or all of our cases that showed significant visual improvement after treatment might also have improved without treatment. The incidence of spontaneous, significant improvement in visual acuity after central retinal artery obstruction is unknown. However, it is well known that occasional cases of acute central retinal artery obstruction without a fovea-sparing cilioretinal artery show a marked recovery of visual acuity without treatment. The authors recognise that further investigation is needed to clarify the efficacy of treatment in these cases. However, we can conclude from our study that a completely dismal prognosis for recovery of useful vision in eyes with acute central retinal artery obstruction is probably unwarranted.

This study was supported in part by the Retina Research and Development Foundation, Wills Eye Hospital, and the Pennsylvania Lions Sight Conservation and Eye Research Foundation, Inc.

\section{References}

1 Brown GC, Shields JA. Cilioretinal arteries and retinal arterial occlusion. Arch Ophthalmol 1979; 97: 84-92.

2 ffytche TJ. A rationalization of treatment of central retinal artery occlusion. Trans Ophthalmol Soc UK 1974; 94: 468-78.

3 Lansche RK. Central retinal artery occlusion. Am J Ophthalmol 1965; 60: 716-9.

4 Kennedy DD, Rosenthal FD, Sneddon IB. Total central retinal artery occlusion successfully treated. $\mathrm{Br} \mathrm{Med} \mathrm{J}$ $1966 ; \mathbf{i}: 32$.

5 Judge TG. Successful remission of central retinal artery occlusion following the use of isoxsuprine. $\mathrm{Br} J$ Clin Pract 1968; 22: 223-4.

6 Varley EWB, Holt-Wilson AD, Chir B, Watson PG. Acute retinal arterial occlusion following reduction of a fractured zygoma and its successful treatment. $\mathrm{Br} J \mathrm{Oral}$ Surg 1968; 6: 31-6.

7 Watson PG. The treatment of acute retinal arteriat occlusion. In: Cant JS, ed. The Ocular Circulation in Health and Disease. St Louis: Mosby, 1969: 234-45.

8 Gombos GM. A new treatment of central retinal axtery. , occlusion. Ann Ophthalmol 1970; 2: 893-6.

9 Stone R, Zink H, Klingele T, Burde RM: Visual recevery. after central retinal artery occlusion. Ann Ophthalmol. 1977; 9: 445-50.

10 Gombos GM. Retinal vascular occlusions and their treatment with low molecular weight dextran and vasodilators. Ann Ophthalmol 1978; 10: 579-83.

11 Younge BR, Rosenbaum TJ. Treatment of acute central retinal artery occlusion. Mayo Clin Proc 1978; 53: 408-10.

12 Magargal LE, Goldberg RE. Anterior chamber paracentesis in the management of acute non-arteritic central retinal artery occlusion. Surg Forum 1977; 28: 518-21.

13 David NJ, Norton EWD, Gass JD, Beauchamp J. Fluorescein angiography in central retinal artery occlusion. Arch Ophthalmol 1967; 77: 619-29.

14 Hayreh SS, Kolder HE, Weingeist TA. Central retinal artery occlusion and retinal tolerance time. Ophthalmology 1980; 87: 75-8.

15 Landers MB III. Retinal oxygenation via the choroidal circulation. Trans Am Ophthalmol Soc 1978; 76: 528-56.

16 Henkes HE. Electroretinography in circulatory disturbances of the retina. Arch Ophthalmol 1954; 51 : 42-53.

17 Lorentzen SE. Occlusion of the central retinal artery. Acta Ophthalmol (Kbh) 1969; 47: 690-703.

18 Karjalainen $\mathrm{K}$. Occlusion of the central retinal artery and retinal branch arteries. Acta Ophthalmol (Kbh) 1971: Supplement 109: 9-92. 